\title{
Peer-led exercise program for ageing adults to improve physical functions - a randomized trial
}

\author{
D. R. Bouchard ${ }^{1,2^{*}}$ D, J. V. Olthuis ${ }^{3}$, V. Bouffard-Levasseur ${ }^{4}$, C. Shannon ${ }^{2}$, T. McDonald $^{5}$ and M. Sénéchal ${ }^{1,2}$
}

\begin{abstract}
Background: A peer-led exercise program is one way to empower people sharing similar characteristics to encourage others to be active, but there is a lack of evidence that these programs have physical function and other benefits when delivered to ageing adults.

Methods: This randomized controlled trial lasting 12 weeks proposed an exercise peer-led program offered to 31 adults aged 50 and above, twice a week, by a trained leader of the same age from March to May 2019. The program was offered for free with limited space and equipment. Valid tests of physical function (e.g., 30-s chair stand, 6-min walk test) were used to assess the functional benefits. Psychosocial outcomes were assessed using selfreported questionnaires and metabolic outcomes via a fasted blood draw.

Results: A significant difference was found between pre-and post-values in most physical function tests in the intervention group (all $p<0.05$ ). When adjusted for potential confounders, the intervention group was significantly associated with a more significant improvement on the chair stand test $\left(B=.26 ; p<0.001 ; r^{2}=0.26\right)$, the arm curl $\left(B=.29 ; p<0.001 ; r^{2}=0.49\right)$, as well as the 6 -min walk test $\left(B=-.14 ; p<0.001 ; r^{2}=0.62\right)$ compared with the control group. Using repetitive measures generalized linear model, the interaction between the changes and the group was significant for all three tests. Benefits were also observed for participants' stress level and perceived health in the intervention group compared to the control. Finally, no significant difference was observed between groups for metabolic health.
\end{abstract}

Conclusions: The current work suggests that a 12-week peer-led exercise program can improve physical function for adults age 50 and above.

Trial registration: NCT03799952 (ClinicalTrials.gov) 12/20/2018.

Keywords: Physical function, Peer-led, Ageing adults, Physical activity, Exercise

\section{Background}

The number of ageing adults is increasing worldwide [1]. Even though there are many known physical and mental health benefits to regular physical activity [2], most adults do not adhere to an active lifestyle. For

\footnotetext{
* Correspondence: Danielle.bouchard@unb.ca

${ }^{1}$ Cardiometabolic Exercise \& Lifestyle Laboratory, Fredericton, NB, Canada

${ }^{2}$ Faculty of Kinesiology, University of New Brunswick, Fredericton, NB E3B 4J9, Canada

Full list of author information is available at the end of the article
}

example, less than $16 \%$ of Canadian adults aged 18-79 reach the national physical activity guidelines when measured objectively [3]. Some have suggested that receiving the exercise program through a peer-leader could lead to benefits by increasing adherence [4].

A peer-leader is a person who shares similar experiences and status to those they are leading [5]. Peer-led exercise programs have shown success in encouraging physical activity [6-8]. This model of delivery is affordable [8], gives a sense of empowerment [9], and

(c) The Author(s). 2021 Open Access This article is licensed under a Creative Commons Attribution 4.0 International License, which permits use, sharing, adaptation, distribution and reproduction in any medium or format, as long as you give appropriate credit to the original author(s) and the source, provide a link to the Creative Commons licence, and indicate if changes were made. The images or other third party material in this article are included in the article's Creative Commons licence, unless indicated otherwise in a credit line to the material. If material is not included in the article's Creative Commons licence and your intended use is not permitted by statutory regulation or exceeds the permitted use, you will need to obtain permission directly from the copyright holder. To view a copy of this licence, visit http://creativecommons.org/licenses/by/4.0/ The Creative Commons Public Domain Dedication waiver (http://creativecommons.org/publicdomain/zero/1.0/) applies to the data made available in this article, unless otherwise stated in a credit line to the data. 
promotes social connectedness [7]. One study even concluded that peer-led exercise programs were as effective as professionally-led exercise programs in the community [6]. However, a systematic review in 2018 reported that although peer-led exercise can promote and maintain adherence to exercise programs, the peer-led exercise programs' impact on physical function was still unclear [10]. Quantifying the impact of peer-led exercise on physical function is essential. It has direct implications for policy and practice decisions about promoting participation in these programs among ageing adults. It is also crucial for funding to support or to subsidize peer-led programs.

\section{Objectives}

This study's main objective was to test the change in participants' physical function, measured by the changes on the 30-s chair stand test, in a 12-week, peer-led exercise program offered to community adults (age 50 and above) as compared to a control condition. The secondary objective was to explore the other physical function tests, and the peer-led exercise program's psychosocial and metabolic benefits.

\section{Methods}

\section{Trial design}

Participants were randomized to receive either the intervention (Spring) or waitlist control (Fall) using concealed envelopes prepared by a third party using a closed container. That container included all 62 papers. A student not related to the project performed the allocation. Peer leaders were blinded to randomization as they did not know that participants in the Spring groups were in the intervention group, and participants in the Fall were in the control group. Participants in the Spring were also invited to participate again in the Fall. Peer-leaders were told that we were limiting the number of participants for space and to start with smaller group sizes for the Spring groups. The participants were blinded as they were not tested after the Fall session, but it was not mentioned.

\section{Recruitment}

To be eligible to participate, individuals had to be at least 50 years, could physically come to the location where the exercise sessions were delivered, be cleared to exercise as determined by the Canadian Society of Exercise Physiology (CSEP) Get Active Questionnaire [11] or by a physician if needed, and participants needed to consider themselves as inactive by confirming not currently being involved in organized physical activity program. Participants were excluded if they were not cleared by a physical activity screening test or did not receive clearance from their primary physician to participate. Finally, participants were not eligible if they participated in the offered peer-led exercise program in the past. The tested peer-led exercise program has existed for many years but has not been appropriately evaluated. Therefore, the same inclusion/exclusion was used, which includes the threshold for age $50+$. Initially, the program was developed to promote independence and prevent falls by long-term participation. Participants were recruited through radio advertisements, newspapers, posters, and social media.

Four peer leaders were recruited using the same strategy based on a first-come, first-served procedure. They were eligible if they reported being a regular exerciser, willing to participate in $32 \mathrm{~h}$ of interactive training sessions offered by the provincial fitness accreditation body over 4 days, and willing to volunteer to offer an exercise program in their community for free. Peer leaders received a manual, along with practical training. A formal background in health or fitness was not required. Continued support was offered to the leaders once they began leading the program. This support was offered through both the provincial fitness accreditation body and the research staff.

Recruitment for all participants (intervention and control) occurred between January and March 2019. When participants called to enrol in the program, they were assessed for eligibility over the phone by the research staff. Those who were eligible were told that they would be randomized into either the Spring (intervention) or the Fall (control) group, but testing would only occur in March and May 2019. The exercise program was offered between March and May 2019 for those randomized to the intervention. It was offered between September and December 2019 for those randomized to the control condition.

\section{Intervention}

The exercise program, called Zoomers on the Go [12], occurred at an indoor community location (e.g., community room, church basement) at no cost to participants. The peer-led exercise program was offered twice a week for 60-min (10-min warm-up, 10-min aerobic exercise, 10-min balance exercises, 15-min of muscle strengthening exercises, 10-min of flexibility activities, and a 5-min cool-down) for 12 weeks. Resistance exercises were done using a coloured TheraBand, a 9-in. sponge ball, and paper plates. There were also chairs available for every participant if needed. More details on the program are presented in the supplementary file.

\section{Primary outcomes}

The primary outcome was strength assessed by the change on the 30-s chair stand test. Participants were asked to sit on the edge of a chair, standing up and sitting down as many times as possible in $30 \mathrm{~s}$. The research assistant recorded the number of repetitions completed during the test [13]. 


\section{Exploratory outcomes}

Besides the 30-s chair stand test, three other Senior Fitness Tests (SFT) were used to explore the program's potential benefits on physical function. These were the 6min walk test (6MWT), the 30 -s arm curl test and the Back Scratch Test. In addition to the SFT battery of tests, the one-leg stance was used to assess a participant's balance, eyes open, and eyes closed [14]. Finally, grip strength was collected using a JAMAR analogue handheld dynamometer (Lafayette Instrument Company, USA) for both left and right hands. The highest value of each hand was added together, according to CSEP [14].

Capillary blood sampling was conducted using the CardioCheck Analyzer device to determine high-density lipoprotein (HDL), triglycerides, low-density lipoproteins (LDL), and glucose [15].

Psychosocial outcomes were assessed via questionnaire. The Depression Anxiety Stress Scales - 21 item (DASS-21) was used to measure past week depression (scores of 13, 20, 27, and 38 indicate mild, moderate, severe, and extremely severe symptoms, respectively), anxiety (scores of 8, 10, 15, and 20 indicate mild, moderate, severe, and extremely severe symptoms, respectively), and stress (scores of 15, 19, 26, and 34 indicate mild, moderate, severe, and extremely severe symptoms, respectively) [16]. The Short Form Health Survey - 36 items (SF-36) was used to measure day-to-day functioning and quality of life [17]. The scale is composed of eight domain subscales (i.e., Physical Functioning, Role Limitations due to Physical Health, Pain, General Health, Energy/Fatigue, Social Functioning, Role Limitations due to Emotional Problems, Emotional Well-Being) scored from 0 (worst) to 100 (excellent).

\section{Potential confounder outcomes}

Demographic data, including age, sex, marital status, occupation, and household income, were assessed via a self-report questionnaire.

Attendance at the peer-led exercise group was collected on-site by the program leader. The maximum number of sessions was 23 as one session was cancelled for a holiday.

Body weight was measured to the nearest $0.1 \mathrm{~kg}$, and height was measured to the nearest $0.1 \mathrm{~cm}$ on a calibrated column scale (SECA model \#213, Hamburg, Germany), using CSEP protocols. Body-mass index (BMI) was calculated using body weight, height and the CSEP equation for BMI. Resting blood pressure and resting heart rate were collected on-site with a portable blood pressure cuff (Omron M1 Plus -HEM-4011C-E).

Physical activity level was objectively assessed using PiezoRxD pedometers (Steps Count, CA) to describe the sample at baseline. Participants were asked to wear the pedometer for seven consecutive days before the start of the program. The pedometer was used to track steps per day and estimate total time spent participating in moderate to vigorous physical activity based on walking cadence. Total time spent at a cadence of a minimum of 120 steps per minute was considered time spent in moderate and vigorous-intensity, respectively [18].

\section{Sample size calculation}

The effect size expected on the chair stand test was determined using clinical data previously collected on 248 participants participating in this program. Despite the high number of participants, this dataset lacked a control group, and testing was done in a clinical setting without rigid testing sessions to respect the 12-week intervention. Some participants who saw changes in the chair stand participated in the program many years before being tested. Nonetheless, an improvement of 1.72 $\mathrm{s} \pm 2.10 \mathrm{~s}$ was observed for the sit-to-stand test (standing from a seated position as fast as possible for five repetitions). Assuming the same proportion as an effect size, that the control group would not improve, with a power of $80 \%$ and an alpha of $95 \%$, it was estimated that 24 people per group were required to observe the same proportion of improvement on the sit-to-stand test. To account for the anticipated drop-out rate (i.e., 30\%) [19], 31 participants were recruited per group.

\section{Data analytic plan}

Differences between groups on descriptive variables and outcomes at baseline were tested via T-tests and Chisquare tests depending on the variable's nature. Changes in physical function were tested using linear regression models. This was done using a stepwise strategy, with the dependent variable being the change pre-post. The independent variables were the treatment group, baseline value on the test, and any differences between groups observed at baseline on descriptive characteristics. General Linear Models repetitive measure tests were used to test how pre and post observations on each functional test were affected by the interaction group*time adjusted for baseline differences in descriptive characteristics. We also explored if the number of sessions attended by participants in the intervention group predicted changes in physical function using linear regression models once adjusted for potential confounders.

\section{Results}

Sixty-two participants took part in the study (31 intervention, 31 control). Three participants $(4.8 \%$; one intervention and two control) dropped out, leaving 59 for analysis (see Fig. 1). Participants reported dropped out because the program was too easy; they had an additional family commitment, or did not want to attend the post-testing session. 
Participants were an average age of 66.1 and 66.6 in the control and intervention groups, respectively. Of those participants, women made up $79.3 \%$ in the control group and $93.3 \%$ in the intervention group. Descriptive information of the sample for participants who completed the intervention is presented in Table 1. At baseline, no difference besides BMI was observed between the two groups on descriptive variables.

Attendance to the exercise sessions averaged $15 \pm 6$ sessions out of 23 sessions (68\%) for participants in the intervention group who completed the post-testing. The number of sessions attended was not associated with any physical function changes when adjusted for age, sex, and baseline value of each physical function.

There was a significant within-group difference found between pre-and post-values in all physical function tests $(p<0.05)$, except for balance (eyes closed) and back scratch test for the intervention group (Table 2). There was group effect for the chair stand $(B=.26 ; p<0.001$; $\left.r^{2}=0.26\right)$, arm curl $\left(\beta=.29 ; p<0.001 ; r^{2}=0.49\right)$, and 6min walk test $\left(B=.14 ; p<0.001 ; r^{2}=0.62\right)$ when models adjusted for baseline value, sex, age and BMI. When using GLM repetitive measures, the interaction group "time for the chair stand $(F=13.85)$, the arm curl ( $F=$ $14.06)$ and the 6 -min walk $(F=16.79)$ was significant (all $p<0.001)$.
For psychosocial outcomes (Table 3), there was a significant within-group difference found between pre-and post-intervention past week stress symptoms $(p<0.05)$ for those in the intervention. There was also a group effect for the past week's stress symptoms $(p=0.01)$. On the SF-36, there was a group effect on General Health, Energy/Fatigue, and Role Limitations due to Emotional Problems, all of which improved significantly more in the intervention than control groups (all $p<0.01$ ). Finally, in terms of metabolic outcomes (Table 4), no differences in pre-post changes were observed between the two groups. However, some improvements were observed for both groups within-groups (e.g., on resting $\mathrm{HR}$, diastolic BP, and glucose).

\section{Discussion}

The current study results support the idea that peer-led exercise programs for aeging adults can lead to physical function improvements. Like previous studies [10, 20, $21]$, the drop-out rate for this program was meagre with a relatively high attendance rate. The combination of low drop-out rates and significant physical function improvements suggests that peer-led exercise programs are a successful intervention for ageing adults living in the community.

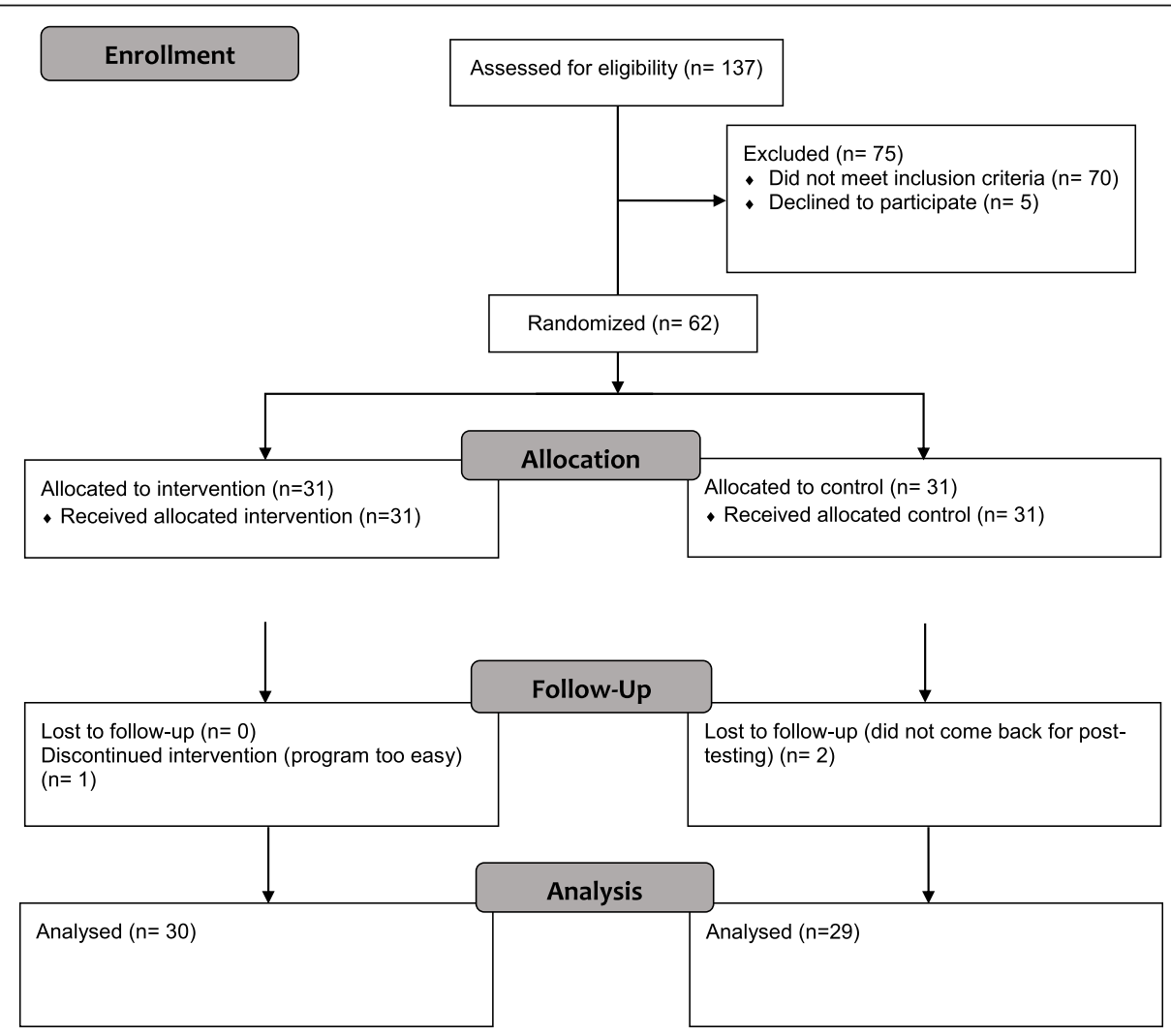

Fig. 1 CONSORT flow diagram of enrollment 
Table 1 Descriptive characteristics of participants

\begin{tabular}{llll}
\hline & $\begin{array}{l}\text { Control } \\
(\boldsymbol{n = 2 9 )}\end{array}$ & Intervention $(\boldsymbol{n = 3 0 )}$ & $\boldsymbol{p}$ value \\
\hline Age (years) & $66.1 \pm 7.0$ & $66.6 \pm 7.2$ & 0.79 \\
$\mathbf{B M I}\left(\mathbf{k g} / \mathbf{m}^{2}\right)$ & $25.8 \pm 4.8$ & $28.9 \pm 4.5$ & 0.02 \\
Women & $23(79.3)$ & $28(93.3)$ & 0.12 \\
Occupation (Retired) & $14(48.3)$ & $19(63.3)$ & 0.15 \\
Marital Status (Married) & $20(69.0)$ & $14(46.7)$ & 0.24 \\
Household Income (>\$100,000/ year) & $6.0(21.0)$ & $6.0(20.0)$ & 0.79 \\
Physical Activity Level (Steps/day) & $7221 \pm 2964$ & $6349 \pm 2903$ & 0.27 \\
Physical Activity Level (MVPA/week) & $48 \pm 81$ & $68 \pm 68$ & 0.51 \\
\hline
\end{tabular}

Data are presented as average \pm SD or $\mathrm{N}(\%)$

Chi Square tests were used to test for potential differences among groups for categorical variables while T-test were used to test for potential differences for continuous variables among groups

Other studies have reported diverse findings [10] on peer-led exercise program's ability to improve physical function. Although the effects of peer-led exercise programs have been systematically reviewed, it is essential to note that many program and participant characteristics can lead to different physical functions. Compared with previous studies looking at the improvement in physical function following a peer-led exercise program, our study involved younger participants (average 66 years) with relatively good health compared to the studies reported in Burton et al. (2018) [10]. Participants in the present study could exercise at a greater intensity than studies involving older participants who observed lower physical function improvements. In support, Dogro et al. (2009; average age 69 years old) reported more improvement for participants who started the program with a greater fitness level [22]. Another essential feature of a peer-led exercise program that leads to physical function improvement seems to be formal training for leaders $[8,22,23]$. It is possible that serious training for peer-leaders, as in the present study, is needed to draw significant physical function benefits.
When discussing peer-led exercise programs, it is essential to note that the literature reports the effects of both peers who deliver the exercise program and peers who encourage ageing adults to become more active. Previous studies have reported that delivering the exercise program by peers is more effective than peers motivating other ageing adults to become more active [24, 25]. It is thus essential to differentiate the two strategies when combining the benefits of a peer-led strategy.

Participants in the intervention group increased the chance of improving their performance on the chair stand, the 6-min walk test, and the arm curls tests by 14 to $29 \%$ regardless of their age, sex, and baseline performance on the test or initial physical activity level. However, the variability at baseline was pretty small, suggesting that participants were already reasonably fit before the intervention. When looking at all participants' percentile level for each test based on age group and sex [13], the average was $55 \%$. This observation suggests that this peer-led exercise program could be more useful for people with lower physical function at baseline, reported before [26]. It is possible that ageing adults who are already more physically active than the average are those

Table 2 Functional Outcomes

\begin{tabular}{|c|c|c|c|c|}
\hline & \multirow{2}{*}{$\begin{array}{l}\text { Control }(n=29) \\
\text { Pre }\end{array}$} & \multicolumn{3}{|c|}{ Intervention $(n=30)$} \\
\hline & & Post & Pre & Post \\
\hline Chair stand (reps/30s) & $13.6 \pm 2.7$ & $14.1 \pm 3.5$ & $14.1 \pm 2.6$ & $17.9 \pm 4.4^{*} \Gamma$ \\
\hline Arm curl test (reps/30s) & $17.3 \pm 4.1$ & $17.4 \pm 3.5$ & $20.1 \pm 5.1 \Gamma$ & $23.9 \pm 4.9 * \Gamma$ \\
\hline Handgrip strength (kg) & $51.4 \pm 15.5$ & $50.1 \pm 17.6$ & $51.8 \pm 14.9$ & $55.3 \pm 15.4^{*}$ \\
\hline Back scratch test $(\mathrm{cm})$ & $-5.2 \pm 9.7$ & $-4.7 \pm 9.9$ & $-7.5 \pm 9.9$ & $-5.7 \pm 9.9$ \\
\hline Timed up and go (s) & $5.3 \pm 0.99$ & $4.9 \pm 1.1^{*}$ & $5.3 \pm 1.2$ & $4.7 \pm 0.9 *$ \\
\hline 6-min walk test (m) & $507 \pm 90.3$ & $504 \pm 79.7$ & $476 \pm 94.3$ & $539 \pm 82.5 * \Gamma$ \\
\hline Balance (eyes opened) (s) & $27.9 \pm 16.4$ & $29.7 \pm 15.6$ & $26.7 \pm 14.4$ & $34.7 \pm 13.4 * \Gamma$ \\
\hline Balance (eyes closed) (s) & $4.9 \pm 3.2$ & $4.4 \pm 2.9$ & $5.0 \pm 3.4$ & $5.3 \pm 3.5$ \\
\hline
\end{tabular}

Data are presented as average \pm SD *significant pre-post changes within groups $(p<0.05)$

$\Gamma$ significant difference in change between intervention and control groups $(p<0.05)$ 
Table 3 Psychosocial outcomes

\begin{tabular}{|c|c|c|c|c|}
\hline & \multicolumn{2}{|c|}{ Control $(n=29)$} & \multicolumn{2}{|c|}{ Intervention $(n=30)$} \\
\hline & Pre & Post & Pre & Post \\
\hline \multicolumn{5}{|l|}{ The Depression Anxiety Stress Scales } \\
\hline Stress (0-14 'normal') & $5.7 \pm 6.2$ & $8.2 \pm 7.7$ & $6.0 \pm 5.6$ & $4.1 \pm 3.9^{*} \Gamma$ \\
\hline Anxiety (0-7 'normal') & $2.6 \pm 4.7$ & $5.0 \pm 7.5$ & $3.5 \pm 3.8$ & $3.2 \pm 3.3$ \\
\hline Depression (0-9 'normal') & $3.2 \pm 3.8$ & $5.5 \pm 9.1$ & $4.8 \pm 6.3$ & $3.2 \pm 5.6$ \\
\hline \multicolumn{5}{|c|}{ Short Form Health Survey (0-100; 100 being best) } \\
\hline Physical Functioning & $80.9 \pm 20.1$ & $80.4 \pm 18.8$ & $78.0 \pm 21.2$ & $81.2 \pm 20.2$ \\
\hline Limitations due to Physical Health & $81.7 \pm 28.8$ & $79.0 \pm 32.8$ & $78.3 \pm 33.9$ & $90.8 \pm 24.1^{*}$ \\
\hline Pain & $79.1 \pm 17.6$ & $71.0 \pm 23.0^{*}$ & $73.5 \pm 22.3$ & $71.9 \pm 20.8$ \\
\hline General Health & $72.4 \pm 11.8$ & $69.8 \pm 16.4$ & $71.2 \pm 19.1$ & $75.5 \pm 15.6^{*} \Gamma$ \\
\hline Energy/Fatigue & $67.4 \pm 18.0$ & $65.4 \pm 17.6$ & $63.5 \pm 19.1$ & $68.7 \pm 16.3^{*} \Gamma$ \\
\hline Social Functioning & $88.9 \pm 16.3$ & $86.4 \pm 19.1$ & $90.2 \pm 14.9$ & $92.1 \pm 13.7$ \\
\hline Limitations Emotional Problems & $78.8 \pm 33.8$ & $84.0 \pm 32.1$ & $84.6 \pm 28.3$ & $88.9 \pm 25.3^{*} \Gamma$ \\
\hline Emotional Well-Being & $82.5 \pm 12.4$ & $78.7 \pm 13.2$ & $80.4 \pm 13.5$ & $84.7 \pm 10.2$ \\
\hline
\end{tabular}

Data are presented as average \pm SD

*significant pre-post changes within groups $(p<0.05)$

$\Gamma$ significant difference in pre-post change between intervention and control groups $(p<0.05)$

who seek out these community programs. Nonetheless, an increase in physical function could lead to greater life expectancy and living independently for a more extended period, as suggested in the literature [27].

The minimally clinically important difference (MCID), within a clinical setting, is the smallest benefit of value to the patient and is not just based on statistical significance but meaningful changes to the individual $[28,29]$. MCID values vary depending on the physical function test and the characteristics of participants. Interestingly, the MCID values for people without clinical conditions are hard to find in the literature. One study conducted with frail ageing adults suggests an MCID of an improvement in $17.8 \mathrm{~m}$ in the 6-min walk test would be clinically significant [30]. While the sample varies from the current study, our findings suggest a mean improvement of $63 \mathrm{~m}$, well above the MCID for the intervention group. Similarly, another study involving ageing adults with COPD [31] reported that the MCID for the 30-s sit-to-stand test would be two repetitions. In comparison, another research conducted with adults undergoing vestibular rehabilitation suggests an improvement of 2.3 $\mathrm{S}$ is clinically meaningful [32], and the intervention group improved the number of stands by 3.8 repetitions. This suggests statistically significant improvement and the clinical significance for ageing adults who participated in this peer-led exercise program.

Findings suggest no significant intervention-specific improvement for metabolic health outcomes, but other studies had reported similar findings when baseline values were relatively average, as in the present study [33]. In contrast, although the present sample reported 'normal' psychosocial functioning at baseline, a more significant improvement was observed in stress for

Table 4 Metabolic Outcomes

\begin{tabular}{|c|c|c|c|c|}
\hline & \multicolumn{2}{|c|}{ Control $(n=29)$} & \multicolumn{2}{|c|}{ Intervention $(n=30)$} \\
\hline & Pre & Post & Pre & Post \\
\hline Resting HR (beats/min) & $68.1 \pm 9.4$ & $63.0 \pm 7.0^{*}$ & $70.5 \pm 6.7$ & $67.2 \pm 7.6^{*}$ \\
\hline Systolic blood pressure (mmHg) & $123.8 \pm 12.6$ & $125.7 \pm 14.9$ & $127.5 \pm 11.1$ & $124.5 \pm 9.5$ \\
\hline Diastolic blood pressure $(\mathrm{mmHg})$ & $77.0 \pm 7.8$ & $72.0 \pm 8.9^{*}$ & $77.0 \pm 6.8$ & $74.5 \pm 6.3^{*}$ \\
\hline HDL cholesterol (mmol/L) & $1.83 \pm 0.41$ & $1.74 \pm 0.37^{*}$ & $1.47 \pm 0.86$ & $1.45 \pm 0.27$ \\
\hline Triglycerides (mmol/L) & $1.30 \pm 0.64$ & $1.24 \pm 0.48$ & $1.91 \pm 1.12$ & $1.66 \pm 0.68$ \\
\hline LDL cholesterol (mmol/L) & $2.88 \pm 1.0$ & $3.2 \pm 0.77$ & $2.83 \pm 1.08$ & $3.03 \pm 0.94$ \\
\hline Glucose (mmol/L) & $5.34 \pm 0.69$ & $4.70 \pm 0.52^{*}$ & $5.61 \pm 1.05$ & $5.11 \pm 0.65^{*}$ \\
\hline
\end{tabular}

Data are presented as average \pm SD

*significant pre-post changes within groups $(p<0.05)$ 
participants in the intervention vs control. Participants in the intervention also reported a more significant improvement in general health, more energy, and fewer role limitations due to emotional problems than those in the control group. A study conducted with 78 ageing adults who participated in a peer-led exercise program also reported an improvement in many domains of the SF-36 despite high baseline scores [21]. According to previous studies, a greater sense of self-efficacy arising from peer-led exercise could, in part, explain a change in health perceptions [9]. Like the metabolic outcomes, a lack of change in anxiety and depressive symptoms in the present study is likely due to the participants' nonclinical nature at baseline. It is possible that ageing adults with greater psychosocial difficulties at baseline would have experienced more significant improvements; however, it is also likely that such individuals would find it more challenging to initiate participation in a peer-led exercise group.

\section{Implications}

Peer-led exercise programs can empower seniors to serve their community. This model of exercise delivery is feasible and can be offered at a low cost. In Zoomers on the Go, the only cost was the provincial fitness accreditation training for leaders and the equipment ( $\$ 15$ per participant). The registration was done by non-profit organizations who also identified a room to offer the free exercise program. The next steps of this program are to impliment the model to be sustainable and study if it is possible to offer it remotely to reach more individuals.

\section{Limitations}

The majority of participants were women suggesting that interventions should be implemented to attract more men to peer-led exercise programs, perhaps by offering an exclusive class for men. The fact that people needed to come to the university facilities for testing two times and regularly attend two weekly exercise sessions may have limited the accessibility of the program for people with lower socioeconomic status. Emotional health was in favour of the control group, compared to the intervention.. Despite these limitations, the study design and the possibility of large-scale implementation of the program are strengths that counterbalance the weaknesses.

\section{Conclusion}

The current work demonstrates the efficacy of a peerled exercise program in improving physical function health among ageing adults. This finding is relevant because of the strong association between physical function and important outcomes such as fall rate, institutionalization, or premature mortality for ageing adults. Future studies need to evaluate the costeffectiveness of peer-led exercise programs, look at strategies to offer these programs in remote areas, and identify how to attract more men.

\section{Supplementary Information}

The online version contains supplementary material available at https://doi. org/10.1186/s11556-021-00257-x.

\section{Additional file 1.}

\section{Abbreviations}

RCT: Randomized controlled trial; SFT: Senior fitness tests; GLM: Generalized linear model; CSEP: Canadian society of exercise physiology; 6MWT: 6-Min walk test; HDL: High-density lipoprotein; LDL: Low-density lipoproteins; DASS-21: Depression anxiety stress scales - 21 item; SF-36: The short form health survey - 36 items; MCID: Minimally clinically important difference

\section{Acknowledgments}

Not applicable.

Authors' information (optional)

Not applicable.

Authors' contributions

The author (s) read and approved the final manuscript.

\section{Funding}

This study is funded by the Government of New Brunswick Wellness Grant; and the New Brunswick Health Research Foundation Grant.

\section{Availability of data and materials}

The datasets used and analyzed during the current study are available from the corresponding author on reasonable request.

Ethics approval and consent to participate

Ethical approval was received from Horizon Health (\#2018-2567).

\section{Consent for publication}

Not applicable.

\section{Competing interests}

None.

\section{Author details}

${ }^{1}$ Cardiometabolic Exercise \& Lifestyle Laboratory, Fredericton, NB, Canada. ${ }^{2}$ Faculty of Kinesiology, University of New Brunswick, Fredericton, NB E3B 4J9, Canada. ${ }^{3}$ Department of Psychology, University of New Brunswick, Fredericton, NB, Canada. ${ }^{4}$ Secteur Éducation et kinésiologie, Université de Moncton, Fredericton, NB, Canada. ${ }^{5}$ Faculty of Law, University of New Brunswick, Fredericton, NB, Canada.

Received: 4 November 2020 Accepted: 31 January 2021

Published online: 11 February 2021

\section{References}

1. He W, Goodkind D, Kowal PR. An aging world: 2015. 2016.

2. Penedo FJ, Dahn JR. Exercise and well-being: a review of mental and physical health benefits associated with physical activity. Curr Opin Psychiatry. 2005;18(2):189-93.

3. Clarke J, Colley R, Janssen I, Tremblay MS. Accelerometer-measured moderate-to-vigorous physical activity of Canadian adults, 2007 to 2017 Health Rep. 2019;30(8):3-10.

4. Rivera-Torres S, Fahey TD, Rivera MA. Adherence to exercise programs in older adults: informative report. Gerontol Geriatr Med. 2019;5:2333721418823604 https://doi.org/10.1177/2333721418823604.

5. Willow $C$, Neale B, editors. Young children's citizenship: ideas into practice. York: Joseph Rowntree Foundation; 2004. 180 p 
6. Adamo DE, Talley SA, Goldberg A. Age and task differences in functional fitness in older women: comparisons with senior fitness test normative and criterion-referenced data. J Aging Phys Act. 2015;23(1):47-54.

7. Hesseberg $\mathrm{K}$, Bentzen $\mathrm{H}$, Bergland A. Reliability of the senior fitness test in community-dwelling older people with cognitive impairment. Physiother Res Int J Res Clin Phys Ther. 2015;20(1):37-44.

8. Wurzer B, Waters DL, Hale LA, Leon de la Barra S. Long-term participation in peer-led fall prevention classes predicts lower fall incidence. Arch Phys Med Rehabil. 2014;95(6):1060-6.

9. Ginis KAM, Nigg CR, Smith AL. Peer-delivered physical activity interventions: an overlooked opportunity for physical activity promotion. Transl Behav Med. 2013;3(4):434-43.

10. Burton E, Farrier K, Hill KD, Codde J, Airey P, Hill A-M. Effectiveness of peers in delivering programs or motivating older people to increase their participation in physical activity: systematic review and meta-analysis. J Sports Sci. 2018;36(6):666-78.

11. Canadian Society for Exercise Physiology (CSEP). Get Active Questionnaire [Internet]. Ottawa: Canadian Society for Exercise Physiology; 2017. Available from: http://www.csep.ca/home

12. Finding Balance. Physical Activity Based Programs, Zoomers on the Go [Internet]. findingbalancenb. 2016 [cited 2020 Jul 8]. Available from: https:// www.findingbalancenb.ca

13. Rikli RE, Jones CJ. Senior fitness test manual. Champaign, IL: Human Kinetics; 2013. p. 202.

14. Canadian Society for Exercise Physiology. CSEP physical activity training for health (CSEP-PATH) resource manual, 2nd edition. 2nd edition. 2020.

15. Ferreira CE dos S, França CN, Correr CJ, Zucker ML, Andriolo A, Scartezini M. Clinical correlation between a point-of-care testing system and laboratory automation for lipid profile. Clin Chim Acta Int J Clin Chem. 2015:446:263-6.

16. Lovibond PF, Lovibond SH. The structure of negative emotional states: comparison of the depression anxiety stress scales (DASS) with the Beck depression and anxiety inventories. Behav Res Ther. 1995;33(3):335-43.

17. Ware Jr JE, Sherbourne CD. The MOS 36-item short-form health survey (SF36). I. Conceptual framework and item selection [Internet]. Vol. 30, Medical care. Med Care; 1992 [cited 2020 Dec 2]. Available from: https://pubmed. ncbi.nlm.nih.gov/1593914/

18. Slaght J, Sénéchal M, Hrubeniuk TJ, Mayo A, Bouchard DR. Walking cadence to exercise at moderate intensity for adults: a systematic review. J Sports Med Hindawi Publ Corp. 2017;2017:4641203.

19. Stiggelbout M, Hopman-Rock M, Tak E, Lechner L, van Mechelen W. Dropout from exercise programs for seniors: a prospective cohort study. J Aging Phys Act. 2005;13(4):406-21.

20. Fishleder S, Petrescu-Prahova M, Harris JR, Leroux B, Bennett K, Helfrich CD et al. Predictors of improvement in physical function in older adults in an evidence-based physical activity program (EnhanceFitness). J Geriatr Phys Ther. 2019;42(4):230-42.

21. Izutsu K, Arima K, Abe Y, Okabe T, Tomita Y, Mizukami S, et al. Exercise intervention implemented by trained volunteers improves health-related quality of life among Japanese community-dwelling older females: an intervention study. J Phys Ther Sci. 2017;29(12):2126-32.

22. Dorgo S, King GA, Brickey GD. The application of peer mentoring to improve fitness in older adults. J Aging Phys Act. 2009;17(3):344-61.

23. Werner D, Teufel J, Brown SL. Evaluation of a peer-led, low-intensity physical activity program for older adults. Am J Health Educ. 2014;45(3):133-41.

24. Sazlina S-G, Browning CJ, Yasin S. Effectiveness of personalized feedback alone or combined with peer support to improve physical activity in sedentary older Malays with type 2 diabetes: a randomized controlled trial. Front Public Health. 2015;3:178.

25. Thomas GN, Macfarlane DJ, Guo B, Cheung BMY, McGhee SM, Chou K-L, et al. Health promotion in older Chinese: a 12-month cluster randomized controlled trial of pedometry and "peer support.". Med Sci Sports Exerc. 2012:44(6):1157-66.

26. García-Hermoso A, Ramirez-Vélez R, Sáez de Asteasu ML, Martínez-Velilla N Zambom-Ferraresi F, Valenzuela PL, et al. Safety and effectiveness of longterm exercise interventions in older adults: a systematic review and metaanalysis of randomized controlled trials. Sports Med. 2020;50(6):1095-106.

27. Enroth L, Raitanen J, Halonen P, Tiainen K, Jylhä M. Trends of physical functioning, morbidity, and disability-free life expectancy among the oldest old: six repeated cross-sectional surveys between 2001 and 2018 in the vitality 90+ study. J Gerontol Ser A. 2020:(glaa144). [cited 2020 Dec 8] Available from: https://doi.org/https://doi.org/10.1093/gerona/glaa144
28. Ibrahim EM, Al-Homaidh A. Physical activity and survival after breast cancer diagnosis: meta-analysis of published studies. Med Oncol Northwood Lond Engl. 2011;28(3):753-65.

29. McGlothlin AE, Lewis RJ. Minimal clinically important difference: defining what really matters to patients. JAMA. 2014;312(13):1342.

30. Kwok BC, Pua YH, Mamun K, Wong WP. The minimal clinically important difference of six-minute walk in Asian older adults. BMC Geriatr. 2013;13(1): 23.

31. Zanini A, Crisafulli E, D’Andria M, Gregorini C, Cherubino F, Zampogna E, et al. Minimal clinically important difference in 30 second sit-to-stand test after pulmonary rehabilitation in patients with COPD. Eur Respir J [Internet]. 2018 Sep 15 [cited 2020 Feb 11];52(suppl 62). Available from: https://erj. ersjournals.com/content/52/suppl_62/OA5199

32. Meretta BM, Whitney SL, Marchetti GF, Sparto PJ, Muirhead RJ. The five times sit to stand test: responsiveness to change and concurrent validity in adults undergoing vestibular rehabilitation. J Vestib Res Equilib Orientat. 2006;16(4-5):233-43.

33. Finucane FM, Sharp SJ, Purslow LR, Horton K, Horton J, Savage DB, et al. The effects of aerobic exercise on metabolic risk, insulin sensitivity and intrahepatic lipid in healthy older people from the Hertfordshire cohort study: a randomised controlled trial. Diabetologia. 2010;53(4):624-31.

\section{Publisher's Note}

Springer Nature remains neutral with regard to jurisdictional claims in published maps and institutional affiliations.
Ready to submit your research? Choose BMC and benefit from:

- fast, convenient online submission

- thorough peer review by experienced researchers in your field

- rapid publication on acceptance

- support for research data, including large and complex data types

- gold Open Access which fosters wider collaboration and increased citations

- maximum visibility for your research: over $100 \mathrm{M}$ website views per year

At BMC, research is always in progress.

Learn more biomedcentral.com/submissions 